\title{
A Scientometric Analysis of Research Advances in China's Eco-Translatology Studies (2008-2021)
}

\author{
Junfang Mu1', Yuyang Chen'1, Guang Yang² \\ ${ }^{1}$ College of Foreign Languages, Hebei University, Baoding, China \\ ${ }^{2}$ The State Key Laboratory of Alternate Electrical Power System with Renewable Energy Sources, North China Electric Power \\ University, Baoding, China \\ Email: Junfangmu@163.com
}

How to cite this paper: Mu, J.F., Chen, Y.Y. and Yang, G. (2021) A Scientometric Analysis of Research Advances in China's Eco-Translatology Studies (2008-2021). Open Access Library Journal, 8: e7791. https://doi.org/10.4236/oalib.1107791

Received: July 26, 2021

Accepted: August 28, 2021

Published: August 31, 2021

Copyright $\odot 2021$ by author(s) and Open Access Library Inc.

This work is licensed under the Creative Commons Attribution International License (CC BY 4.0).

http://creativecommons.org/licenses/by/4.0/ (c) (i) Open Access

\begin{abstract}
Eco-translatology is an interdisciplinary study of ecology and translation. With the help of CiteSpace developed by Professor Chen Chaomei and other statistical tools, this paper draws a knowledge graph of journal papers in the CNKI database of eco-translatology from 2008 to 2021, aiming to vividly and intuitively show the general situation. These hot spots and evolving trends in eco-translatology studies are under widespread scrutiny and investigation by Chinese authors. By dissecting the distribution of papers by the year of publication, co-occurrence keywords network, keyword betweenness centrality and the distribution of articles by institutions, the study has discovered that foreign propaganda translation and public signs translation are key research domains of eco-translatology, thus the interaction between Chinese authors and institutions in various institutions is generally presented.
\end{abstract}

\section{Subject Areas \\ Information Retrieval}

\section{Keywords}

Eco-Translatology, CiteSpace, Visualisation Analysis, Research Frontiers

\section{Introduction}

As an emerging discipline, eco-translatology is an interdisciplinary study of ecology and translation. Its generation and development conform to the trend of global ecological research, as well as that of translation research. Proposed by $\mathrm{Hu}$ 
Gengshen, eco-translatology is a philosophy of translation based on adaptation, devoted to a comprehensive description of translation activities from the perspective of ecology, focusing on the text ecology, the translation ecology, the ecology of "translation community" and their communications and interrelationships, carrying out across-field integrated research [1]. Studied by numerous scholars, eco-translatology is a comprehensive study of translation from the standpoint of ecology which will be discussed further from the connection of ecology and translation in the following sections: in practice research, Ma Jing studied the English translation of public sign [2]; Liu Wenting and Meng Hongmiao analyzed English translation of culture-loaded words in tourism texts using Eco-translatology [3]; Wang Yue and Ji Xiaowen discussed translation strategies of animated film titles from the perspective of eco-translatology [4]. In theoretical research, Hu Gengshen pointed out the research foci and theoretical tenets of eco-translatology [5]; Zhang Lifeng and Jin Wenning discussed the eco-translatology's three ecological dimensions [6]; Hu Gengshen and Tao Youlan proposed a comparative study on approaches to translation studies based on eco-translatology [7]. Nevertheless, there are few reviews based on scientometric studies in this area. This paper attempts to use scientometrics methodology to answer the following questions:

1) Is there a promising research future for eco-translationology?

2) What are the research hotspots in eco-translatology?

3) What is the state of cooperation between eco-translatology researchers and research institutions?

\section{Theoretical Foundation}

\subsection{Theoretical Foundation of Ecology}

Classic ecology considers the ecosystem as the main unit, separated into producers, consumers, and decomposers. Man is a vital link in the ecological food chain. According to the particular ecological niche of humans in the ecosystem, the ecosystem structure composed of producers, consumers, decomposers and regulators is delivered. Through the research of "human ecological niche" and "the quadruple structure of ecosystem", it is not difficult to find that human has played a significant role in linking quaternary structure. As omnivorous consumers, humans engage in energy flow and material circulation in the natural subsystem.

In contrast, humans are the regulators, and they control other components of the natural subsystem in economic activities and social operation according to their financial demands and social desire. The creation and development of contemporary ecology can be considered to be distinguished by the formation and prominence of the human ecological niche. Continuous scientific and technical advancements and innovations have made ecological science make remarkable progress in research approaches. In the current field of ecological research, muchadvanced observation equipment, data analysis software (such as SAS) and statistical analysis models provide an essential platform for the accurate quantita- 
tive data acquisition and scientific processing; the hardening process of the soft ecological system is realised through transforming qualitative factors into semiquantitative and quantitative aspects [8].

\subsection{Theoretical Foundation of Translatology}

Generally speaking, translation has two basic systems: narrow sense and broad sense. In the narrow sense, the translation system is the system of the main body. When the system is far removed from practice and has a low degree of abstraction, the system is separated into five subsystems: meta-theory, translation philosophy, translation theory, translation strategy, translation methodologies and translation skills [9]. On the other hand, the system in the broad sense is termed as the discipline system, which contains profound notions of discipline, discipline standard system, discipline management and legal system [9]. In general, since the 1970s, experts in the international translation field have been examining the meaning, objectives and techniques of translation, and translation theory has been growing. Especially while the "interdisciplinarity" of translation is becoming increasingly prominent and being paid attention to by academics in the translation field, translation research has also shown unprecedented prosperity in different disciplines, different approaches, and schools of linguistics culturology, diplomacy and other areas.

\subsection{Eco-translatology}

The notion of "translation ecological environment" was initially staged in 2001. In 2004, Chinese scholar Hu Gengshen precisely proposed the notion of "translation ecological environment" [10], thereby developing the prototype of the term "eco-translatology". As the discipline evolved, the exact term of eco-translatology was designed by Hu Gengshen in 2008. In 2009, he publicly announced the "ecological shift" of translatology, which is worth notifying that its associated study is still prevalent. Based on the evolutionism of Darwinian, Hu Gengshen defined eco-translatology: "Eco-translatology is a form of eco-translatology view" [11].

Focusing on the integrity of the translation ecology, this definition interprets the translation process from the perspective of the translation ecological environment, describes the relationship between the translator and the translation ecological environment, and attaches great importance to the living situation of translators and the development of their translation ability.

Given the relevance of eco-translatology, it is vital to outline its development trajectory and hot subjects of its studies. According to the literature review, there are limited Scientometric analyses of eco-translatology based on China National Knowledge Infrastructure. This article will conduct a visual analysis of Chinese eco-translatology research using the CNKI database, focusing on three aspects: the chronological distribution of eco-translatology literature, the distribution of eco-translatology research hotspots, and the distribution of prominent eco-translatology authors and institutions. 


\section{Statistics and Methods}

The CNKI database is used as the data source in this article. As shown in Figure 1 , the paper is started using TOPIC search, which included title, abstract, author keywords and keywords plus and was selected to search for the relevant information. Then we search the topic "eco-translatology" in the column of the journal, with "Chinese" as the language. Since the notion of eco-translatology was introduced in 2008, the designated period is from 2008 to 2021. By Additional filtering of irrelevant choices, a total of 1,724 articles are finally derived. Each reference includes the author's name, agency, keywords, title, abstract, bibliography, and publication year.

This article mainly uses CiteSpace as a statistical tool. CiteSpace is a visual information analysis software based on the JAVA platform developed by Professor Chaomei Chen from Drexel University in Philadelphia [12]. It is extensively used in data analysis and Information visualisation analysis and anticipating future trends and breakthroughs in scientific research. CiteSpace has grown to be the most prominent data visualisation program in data mining, information analysis and graphics rendering technology in recent years. CiteSpace's primary distinguishing feature is its in-depth collection, mining, and comprehensive analysis of cited works of literature in the current scientific research, enabling it to clarify the framework structure of the scientific research knowledge and uncover its development and research trends and present its complete display intuitively.

Using the "Export/Reference" tool, this research attempts to download 1,724 reference document data in the document format of pure electronic text reference and convert all documents to essential CiteSpace document types "download_xxx.txt”. Using CiteSpace to analyse the keywords in 1,724 papers, this article interprets the maps of the reference on eco-translatology from 2008

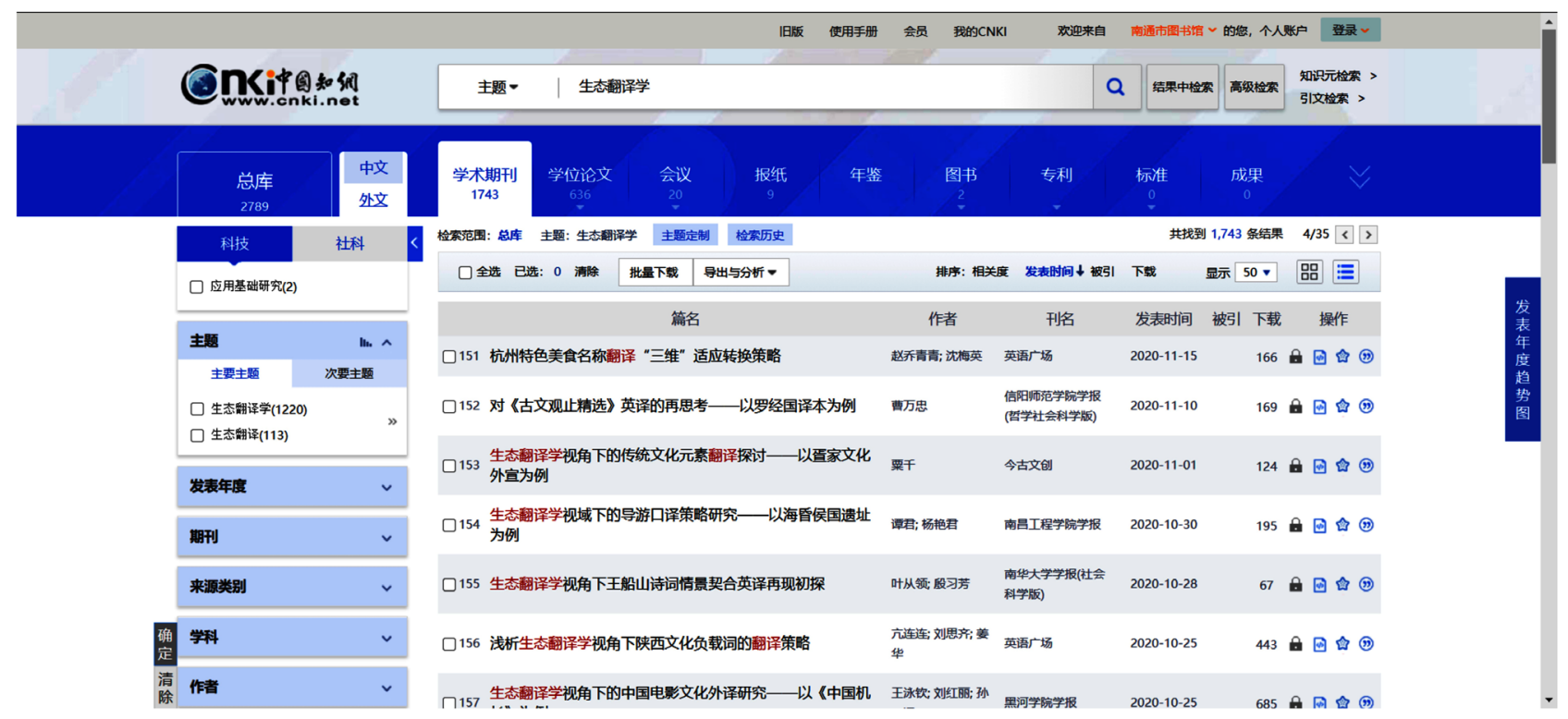

Figure 1. Search results in CNKI database (source: sreenshot in Chinese from www.cnki.net). 
to 2021, including the time distribution of eco-translatology papers, the keyword co-occurrence map, the keyword betweenness centrality table, and the distribution of eco-translatology authors and institutions. These maps are used to conduct a deep analysis of the hotspot, development trend and the current academic changes in eco-translatology research and education.

\section{Data Analysis}

This chapter will make a thorough analysis from the perspective of published journals, research hotspots and distribution of Essential Authors and Institutions.

\subsection{Quantitative Analysis of Published Journals on Eco-Translatology Based on the CNKI Database}

This section attempts to present quantitative analysis of published journals related to the field of eco-translatology based on CNKI database.

Figure 2 depicts the aggregate statistics of academic literature collation closely connected to the subject search "eco-translatology" from 2002 to 2021 . Chinese research on eco-translatology, as seen in Figure 2, can be broadly classified into four distinct phases of development: $2008-2010$ is a time of initial development; 2014-2014 is a time of fast expansion; 2015-2018 is a time of stability; 2018-2021 is a time of secondary growth. According to the general situation in China, a significant number of Chinese papers have been published since about 2011. Although there has been a general reduction in the last few years, the declines will not exceed 50 papers. In 2008-2010, the number of papers published stayed below twenty, with only one article published by Hu Gengshen in 2008. In 2011-2014, eco-translatology research grew at a breakneck pace, with a record reaching more than 190 publications a year. The number of papers on eco-translatology has already grown significantly compared with 2008 since 2015 and it remains a steady pace. However, in 2019 it reached a new level. Throughout the period from 2019 to 2021, the amount of eco-translatology papers rose considerably. Thus,

Quantity of paper

250

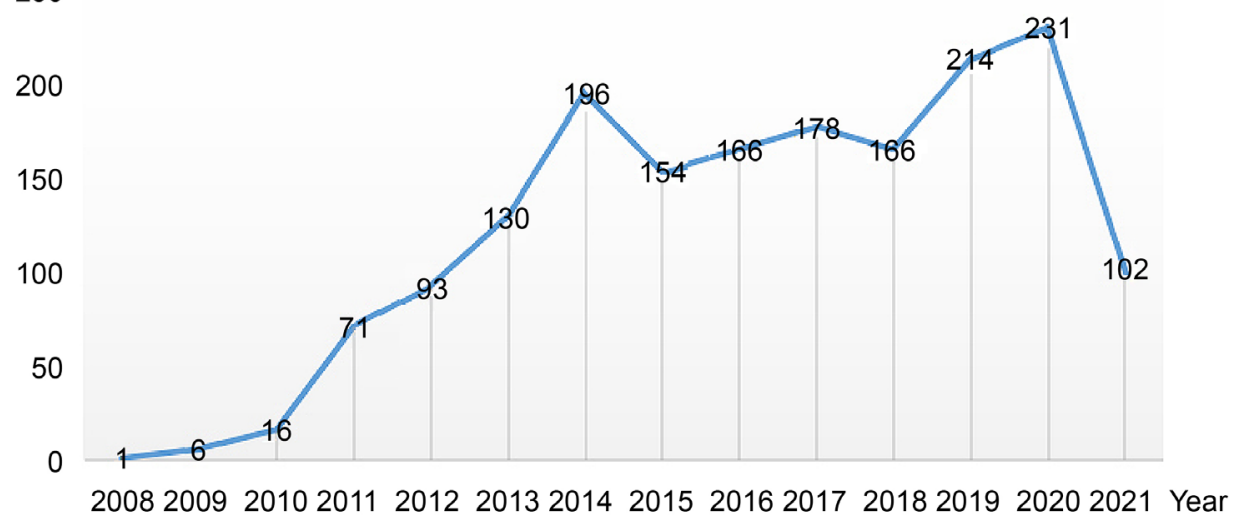

Figure 2. Distribution of journals related to eco-translatology by publishing time. 
Chinese authors' interest in eco-translatology began in 2008 and steadily increased since 2010. Following a period of stable growth, the succeeding research has accelerated its pace of development since 2018, with a generally hopeful outlook for future growth.

\subsection{Distribution of Essential Authors and Institutions in the Field of Eco-Translatology}

CiteSpace's co-citation network analysis enables it to trace the evolution of a discipline or field of inquiry. By utilising time slicing, the time zone examined is separated into multiple time subdivisions. For each partition, a snapshot of the co-citation network is obtained, and then the sequence of images is combined to build a panoramic co-citation network. This progressive analytical methodology can be used to capture and represent the developmental tendency and frontier dynamics of a given discipline or field of knowledge across time, hence establishing the evolution process of several research frontiers [13].

We separate the period 2008-2021 into thirteen time slices. The top 50 authors and institutions published in each time slice are utilised; Minimum Spanning Tree is used to build a visual map of the authors and institutions by pruning the sliced network and pruning the merged network. The threshold is set to 5 . The circle (the node) in the graphic depicts the authors and the authors' institution, and the size of the node indicates the number of papers published by the scholar or institution. The larger the node, the larger the number of articles published by the author or institution. The link between the nodes indicates the relationship between the author and the institution and the relationship between the authors. As shown in Figure 3, there is a relationship between “胡庚申”(Hu Gengshen), “陶李春” (Tao Lichun) and “清华大学” (Tsinghua University) indicating that

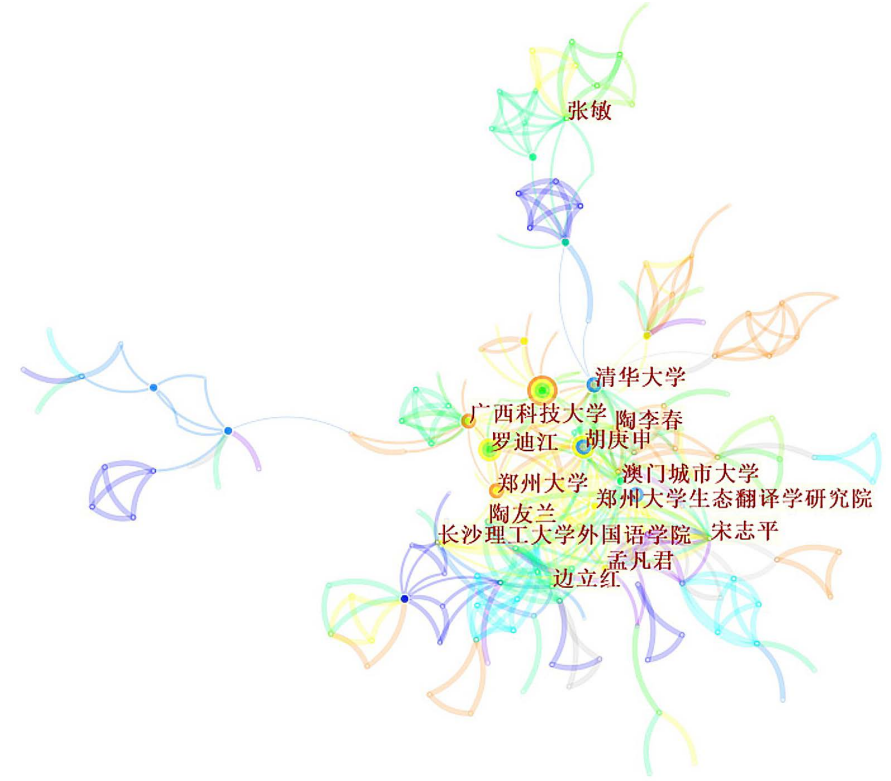

Figure 3. Distribution of important authors and institutions in the field of eco-translatology. 
Hu Gengshen and Tao Lichun collabo rated on a paper. Tsinghua University, Guangxi University of Science and Technology, City University of Macau, Changsha University of Science and Technology, Zhengzhou University, and Nanjing Forestry University are among the institutions with the most research achievements in eco-translatology. Besides, Hu Gengshen, Tao Lichun, Luo Dijiang, Zhang Min, Tao Youlan, Song Zhiping, and Bian Lihong are more prolific authors. Hu Gengshen and Song Zhiping, for example, focus on several critical issues in the field of eco-translatology studies, such as translatability, retranslation, and "turnabout" problems [14]; Luo Di Jiang, Tao Yulan, and Tao Lichun explained the "quadruple-translation doctrine", proposed the concept of "life" behind the "quadruple-translation doctrine" which essentially revealed the deepening research of eco-translatology towards "life" [15]. The majority of authors work collaboratively and have a teamwork attitude in the field of eco-translatology.

\subsection{Research Hotspots of Eco-Translatology}

The keyword co-occurrence map of the Chinese research study on eco-translatology is shown in Figure 4. The keyword co-occurrence map accurately reflects the changing characteristics of the link structure between various keywords, highlights significant links between keywords and the critical nodes, and enables us to observe the eco-translatology discipline's historical dynamics and research trend over time. The 1724 selected articles were imported into CiteSpace, with each time slice set to one year. The study period was set to 2008-2021, with a total of 13 time zones. As we set the node type as "Keyword", the nodes in this study solely represent keywords. In each time slice of keyword, set the relevant frequency to the top $10 \%$ and the article number to less than or equal to 50 . The pruning

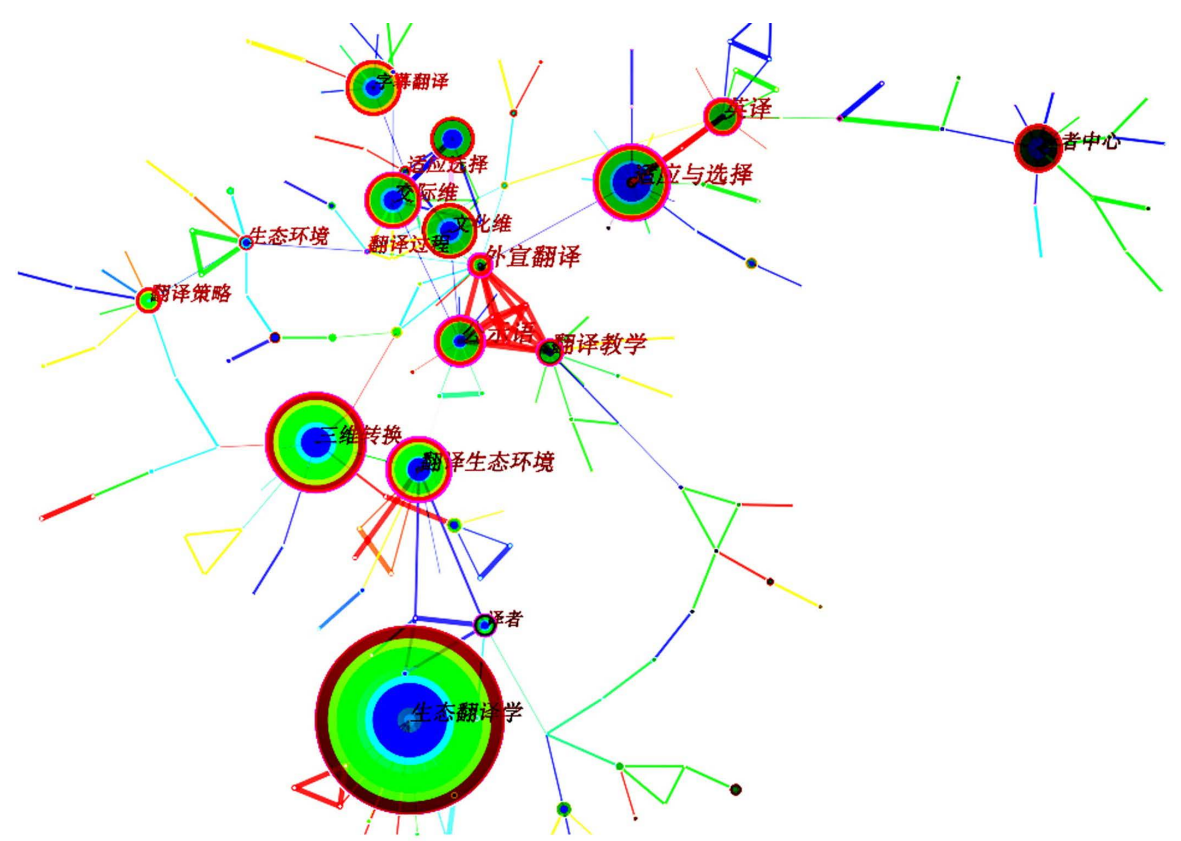

Figure 4. The keyword co-occurrence map of the Chinese research study on eco-translatology. 
method was set as pathfinder. Finally, set the threshold to 6, deleted unrelated nodes and merge relevant nodes to obtain the keyword co-occurrence map of Chinese eco-translatology research literature.

In the network, a circle node represents a keyword. According to the CiteSpace nodes and image processing features, a node's annual ring arrangement structure corresponds to the time period during which the literature relevant is extensively referenced. The thickness of an annual ring is proportional to the number of citations in a time zone [16]. Thus, as one slice of the annual ring radius of keyword node decreases, another slice of keyword node radius will undoubtedly increase; equivalently, the keywords of the node or the total citation frequency of relevant literature in this year increases, also indicating that the node's attention and degree increase. A ring inside a single keyword node often incorporates various forms and colours, signifying the year in which each node keyword will occur; from inside to outside, the colour gradually undergoes a transition from a cold hue to a warm hue. Cold colours indicate a boom phase for older scientific findings, while warm colours suggest the arrival of fresh ones. The thickness of the ring indicates the frequency that a term appears in a particular time zone: the more times a keyword appears, the thicker the ring. The link between nodes implies that there must be an underlying co-occurrence between them. The thicker the line between co-occurring keywords, the more frequently the co-occurring keywords are to appear in the same academic paper. The colour of the line between each co-occurring node corresponds to the specific period of the initial co-occurrence [17].

Each keyword node in Figure 4 represents a different term. Each keyword node's size and colour are related to the keyword's frequency and duration; the more frequently the keyword appears, the larger each node is. According to the frequency of keywords created automatically by CiteSpace, there are 17 keywords with a frequency of at least six.

Along with the theme word "eco-translatology", the keywords with high frequency and betweenness centrality in the map include translator centre, three-dimensional transformation, translational eco-environment, translation strategy, translation teaching, translation of international publicities, translation of public signs, subtitle translation, adaptation and selection, and so on. By analysing, summarising, and classifying keywords in conjunction with existing literature, the study of hotspots in Chinese eco-translatology research involves applying eco-translatology theory, including the translation of international publicities, translation of public signs. Besides, the fact that the node of international publicities translation and that of public signs translation are closely linked to the node of translation teaching demonstrates the great importance of Chinese scholars in cultivating applied translation talents. It is worth mentioning that many Chinese authors have been interested in subtitle translation, indicating another significant area of eco-translatology in the media era. In terms of eco-translatology theory, we can see that the "translator centre," "three-dimensional transformation," and "ad- 
aptation and selection" theories have emerged as significant study objectives.

In contrast, other theoretical points become less prevalent. Due to the crossover situation between each research hotspot, the keywords contained within each hotspot also have a crossover situation, indicating that there is frequently overlap between each research, and Chinese scholars tend to investigate eco-translatology problems from a variety of perspectives. Simultaneously, as the picture indicates, the node colour typically trends toward a warm hue, suggesting that the keywords recently appeared in the literature, showing that the Chinese research of eco-translatology has significant development potential.

Table 1 summarises the top 42 keywords with the highest betweenness centrality in the field of eco-translatology based on CiteSpace statistics. Betweenness centrality is a measure of a keyword node's relevance in a network. CiteSpace may be used to mine pivotal points by calculating the nodes' betweenness centrality and strategical network. The nodes' central roles symbolise keywords' capacity to

Table 1. Keyword betweenness centrality in the field of eco-translatology.

\begin{tabular}{|c|c|c|c|c|c|}
\hline No. & Keywords & Centrality & No. & Keywords & Centrality \\
\hline 1 & International publicity translation & 0.59 & 22 & Adaptive selection & 0.08 \\
\hline 2 & Public signs translation & 0.52 & 23 & The "three-dimensional" principle & 0.08 \\
\hline 3 & Translational eco-evironment & 0.51 & 24 & Ecological balance & 0.08 \\
\hline 4 & Adaptation and selection & 0.43 & 25 & Three dimensions & 0.08 \\
\hline 5 & Translators & 0.32 & 26 & Literary translation & 0.08 \\
\hline 6 & English translation & 0.31 & 27 & Film titles & 0.07 \\
\hline 7 & Three-dimensional translation & 0.24 & 28 & The cultural dimension & 0.06 \\
\hline 8 & The communication dimension & 0.24 & 29 & Principles of translation & 0.05 \\
\hline 9 & The translation process & 0.22 & 30 & "One Belt, One Road" & 0.05 \\
\hline 10 & Teaching translation & 0.21 & 31 & Interaction & 0.05 \\
\hline 11 & Koo Hong Ming & 0.2 & 32 & $\begin{array}{c}\text { The Yellow Emperor's Canon of Internal } \\
\text { Medicine }\end{array}$ & 0.05 \\
\hline 12 & Adaptive selection & 0.19 & 33 & Translation of film subtitles & 0.05 \\
\hline 13 & The analects of confucius & 0.18 & 34 & Sichuan Miao culture & 0.05 \\
\hline 14 & English translation of public signs & 0.17 & 35 & Culture-loaded words & 0.04 \\
\hline 15 & Eco-translatology & 0.16 & 36 & Multidimensional translation & 0.04 \\
\hline 16 & Translator centre & 0.16 & 37 & Ecology of translation & 0.04 \\
\hline 17 & Ecological environment & 0.16 & 38 & Adaptive selection of translations & 0.04 \\
\hline 18 & Translation methodology & 0.15 & 39 & Tourism & 0.04 \\
\hline 19 & Subtitle translation & 0.13 & 40 & Interpreting & 0.04 \\
\hline 20 & Translation strategies & 0.11 & 41 & Li Jiye & 0.04 \\
\hline 21 & Tourist attractions & 0.09 & 42 & Theoretical foundations & 0.04 \\
\hline
\end{tabular}


act as the network's "centre", which is the capacity to occupy the shortest path between the other two nodes. Once the node has vanished and the remaining two nodes are unable to connect. When more nodes are connected, the higher the betweenness centrality of this node becomes. It serves as a strategic mediator across the network and represents its influence over the network's entire resources. The higher the intermediary keywords' betweenness centrality, the larger the information flow between the keyword controlled by the intermediary keywords [18]. CiteSpace utilises this indication to identify and quantify keywords' relevance, identify research hotspots, and emphasis these keywords with a purple circle.

According to Figure 4, the keyword with the highest betweenness centrality is "international publicity translation" and the second keyword is "public sign translation", followed by "Translational eco-environment", "adaptation and selection", "translator", "English translation", "three-dimensional transformation", and "communication dimension", which corresponds to the previous CiteSpace scientometric map's findings. "International publicity translation" and "public sign translation", as the two keywords with highest betweenness centrality, build bridges between the other keywords in literature, which denotes the Chinese eco-translatology theory research essentially develop around the two themes, reflecting the Chinese eco-translatology theory research preference for applied translation research in recent years, as well as the scholars' attention to the field of public discourse.

\section{Conclusion}

CiteSpace, a visual scientometric tool, helps to gain a clear understanding of the significant research hotspots in eco-translatology and the contribution made by academia to Chinese translatology studies. Chinese academics have undertaken a multidimensional analysis of eco-translatology as well as its applied research. We look forward to doing further study in this area, demonstrating the academic merit and translation philosophy of eco-translatology, and promoting the culture and image of China.

\section{Acknowledgements}

The authors would like to thank Hebei Youth Top-notch Talents Project (BJ2020089) and supported by Hebei Province Innovation Capability Improvement Plan Project (21557612K).

\section{Conflicts of Interest}

The authors declare no conflicts of interest.

\section{References}

[1] Hu, G.S. (2008) Eco-Translatology: A Primer. Chinese Translators Journal, 6, 11-15+92.

[2] Ma, J. (2014) The English Translation of Public Signs in Qingdao-From the Perspective of Eco-Translatology. Theory and Practice in Language Studies, 4, 2527-2532. https://doi.org/10.4304/tpls.4.12.2527-2532 
[3] Liu, W.T. and Meng, H.M. (2018) A Study on English Translation of Culture-Loaded Words in Tourism Texts from the Perspective of Eco-Translatology. Studies in Literature and Language, 17, 105-108. http://dx.doi.org/10.3968/10509

[4] Wang, Y. and Ji, X. (2021) A Study of Translation Strategies of Animated Film Titles from the Perspective of Eco-Translatology. Journal of Language Teaching and Research, 12, 88-98. https://doi.org/10.17507/jltr.1201.09

[5] Hu, G.S. (2011) Eco-Translatology: Research Foci and Theoretical Tenets. Chinese Translators Journal, 2, 5-9.

[6] Zhang, L.F. and Jin, W.N. (2011) Eco-Translatology and Its Three Ecological Dimensions-A Discussion with Prof. Hu Gengshen. Journal of University of Shanghai for Science and Technology (Social Sciences Edition), 33, 261-266.

[7] Hu, G.S., and Tao, Y.L. (2016) Eco-Translatology: A New Paradigm of Eco-Translation-A Comparative Study on Approaches to Translation Studies. Sociology, 115-132.

[8] Geng, X.P. (2017) Eco-Translatology \& Its Criticism System. Jilin People’s Press, Changchun.

[9] Hu, G.S. (2013) Eco-Translatology Construction \& Interpretation. The Commercial Press, Beijing.

[10] Hu, G.S. (2004) An Approach to Translation as Adaptation and Selection. Hubei Education Press, Wuhan.

[11] Hu, G.S. (2009) Eco-Translatology: “Cross-disciplinary Integration” of Translation Studies. Shanghai Journal of Translators, 2, 3-8.

[12] Meng, W., Shen, K. and An, Q. (2015) Visual Analysis of Real Estate Investment Trusts Research-A Bibliometric Analysis Based on CiteSpace III. American Journal of Industrial and Business Management, 5, 794-805. http://dx.doi.org/10.4236/ajibm.2015.512076

[13] Chen, C.M. (2006) CiteSpace II: Detecting and Visualizing Emerging Trends and Transient Patterns in Scientific Literature. Journal of the American Society for Information Science and Technology, 57, 359-377. https://doi.org/10.1002/asi.20317

[14] Song, Z.P., Hu, G.S. (2016) Interpretation of Some Key Issues in Translation Studies from Perspective of Eco-Translatology. Foreign Language Education, 37, 107-110.

[15] Luo, D.J., Tao, Y.L. and Tao, L.C. (2019) A New Interpretation of "Quadruple-Translation Doctrine" of Eco-Translatology. Journal of Poyang Lake, 6, 12-18+125.

[16] Liu, S., Sun, Y.P., Gao, X.L. and Sui, Y. (2019) Knowledge Domain and Emerging Trends in Alzheimer's Disease: A Scientometric Review Based on CiteSpace Analysis. Neural Regeneration Research, 14, 1643-1650. https://doi.org/10.4103/1673-5374.255995

[17] Chen, Y., Chen, C.M., Hu, Z.G., et al. (2014) Principles and Application of Analysing a Citation Space. Science Press, Beijing.

[18] Small, H. (1986) The Synthesis of Specialty Narratives from Co-Citation Clusters. Journal of the American Society for Information Science, 37, 97-110. https://doi.org/10.1002/(SICI)1097-4571(198605)37:3<97::AID-ASI1>3.0.CO;2-K 